A N N A L E S Annales de Bretagne et des Pays de l'Ouest

Anjou. Maine. Poitou-Charente. Touraine

112-1 | 2005

Varia

\title{
Nicole de Blomac, Voyer d'Argenson et le cheval des
}

\section{Lumières.}

\section{Brigitte Maillard}

\section{OpenEdition}

1 Journals

Édition électronique

URL : http://journals.openedition.org/abpo/1165

DOI : $10.4000 / a b p o .1165$

ISBN : 978-2-7535-1497-3

ISSN : $2108-6443$

Éditeur

Presses universitaires de Rennes

Édition imprimée

Date de publication : 20 mars 2005

Pagination : 182-184

ISBN : 978-2-7535-0125-6

ISSN : 0399-0826

Référence électronique

Brigitte Maillard, « Nicole de Blomac, Voyer d'Argenson et le cheval des Lumières. », Annales de Bretagne et des Pays de l'Ouest [En ligne], 112-1 | 2005, mis en ligne le 20 mars 2007, consulté le 23 septembre 2020. URL : http://journals.openedition.org/abpo/1165; DOI : https://doi.org/10.4000/abpo.1165 
privilégié des femmes, a longtemps été un des éléments de base de la polyactivité rurale largement répandue en France. Enfin les pages pittoresques de C. Guintard et C Mazzoli-Guintard, en étudiant une maxime juridique qui figure dans un recueil publié à Cordoue au début du $x^{e}$ siècle, rappellent que le voisinage de différents animaux était parfois à l'origine de problèmes juridiques : ainsi un pigeonnier et une ruche doivent être placés à bonne distance l'un de l'autre pour éviter que les volatiles ne soient piqués par les abeilles, animaux que l'homme peut élever mais non domestiquer...

Les historiens de toutes les périodes apprendront beaucoup dans ces contributions; dans de nombreuses pages est évoqué le passé des relations des animaux avec les hommes et le milieu, puisque les races d'animaux domestiques sont des produits des sociétés humaines. Ils pourront y trouver une incitation à explorer ces domaines encore délaissés.

Brigitte MAILLARD

Blomac, Nicole de, Voyer d'Argenson et le cheval des Lumières, Paris, Belin, coll. " Histoire et Société ", 2004, 398 p., $23 €$.

Le cheval est au centre des intérêts de N. de Blomac comme il le fut pour Marc-René de Voyer de Paulmy d'Argenson, dit le marquis de Voyer. Servie en cela par l'expérience pratique qu'elle a de ce monde, elle s'attache en effet de puis plusieurs années à écrire l'histoire de cet animal, chargé plus que tout autre d'un fort sens symbolique, puisqu'il est souvent identifié à la noblesse, car ce n'est pas du cheval utilisé par certains paysans qu'il est question; mais de cette monture destinée à remplir les besoins des armées servir, à servir aux cavaliers civils pour une équitation de loisirs (chasse, courses) et à l'éducation des jeunes nobles (dans les académies d'équitation), à répondre aux nouveaux besoins des transports.

Comment mieux écrire l'histoire des premières tentatives pour créer en France une nouvelle espèce de cheval, le " pur sang " qu'en étudiant l'histoire et l'œuvre du marquis de Voyer (1722-1782), cet aristocrate qui, en s'inspirant de l'exemple britannique, tenta de créer un cheval de race en France. Dans cet ouvrage très documenté, N. de Blomac utilise en particulier les très riches archives de la famille d'Argenson. On peut regretter l'absence d'une fiche bibliographique (les indications sont à retrouver dans les notes); il faut aussi noter différentes inexactitudes dans les localisations géographiques (aussi bien dans le courant du texte que dans la carte p. 336).

Est mise en évidence l'œuvre originale, mais inscrite dans son temps, du descendant d'une vieille famille noble qui arriva jusqu'aux postes ministériels (son père, le comte d'Argenson, fut lieutenant de police de Paris deux fois, intendant de la généralité de Tours, secrétaire d'État à la guerre entre 1743 et 1757 , date de sa disgrâce; son oncle, le marquis d'Argenson, fut secrétaire d'État aux Affaires étrangères). La famille d'Argenson était aussi fortement enracinée dans un espace régional aux confins du Poitou et de la Touraine, le comte d'Argenson puis son fils y constituèrent par différentes voies un très vaste domaine, érigé en 1732 en baronnie avec son siège aux Ormes. Voyer lui manifesta toujours un grand attachement et y réalisa son dessein de fonder un haras.

La carrière militaire de Voyer s'annonçait prometteuse puisque dès 1745 il était promu général mais elle s'arrêta là puisqu'il ne fut jamais nommé maréchal 
(la faute en revint sans doute à son attitude critique pendant la guerre dite de Sept Ans et sa liberté de parole, ainsi qu'à l'hostilité de madame de Pompadour, qui toucha aussi son père). Proche du duc d'Orléans il fréquenta les milieux de la cour, se créant ainsi un vaste réseau de relations. Il fit un riche mariage en épousant madame de Mailly qui lui apporta une belle dot et lui permit d'entrer dans la parentèle des Colbert; mais les rapports conjugaux furent tendus, car son épouse n'approuvait pas les risques financiers qu'il prenait et une demande en séparation de biens fut engagée en 1760. Mais en 1771, il eut le bonheur de voir naître après trois filles un fils, qui perpétua le nom. Il mourut en 1782 à 60 ans, d'une " fièvre méphitique " contractée dans les marais de Rochefort, dont il voulait faire réaliser l'assèchement pour lutter contre le fléau qui ravageait officiers et soldats.

Il s'inscrit dans son temps de bien des manières. Animé d'une grande curiosité intellectuelle il se constitua une vaste bibliothèque et une très belle collection de tableaux; il fut habité par la passion des bâtiments (construction du château d'Asnières à partir de 1750 et par l'architecte de Wailly, de magnifiques bâtiments aux Ormes). Il fut aussi un homme d'action au service de l'État (il fut très longtemps Inspecteur de la cavalerie et des dragons et de 1750 à 1763 directeur général de l'administration des Haras, créée par Colbert en 1665) mais il participa aussi au mouvement d'agronomie à la fois comme théoricien (il rédigea de très nombreux écrits qui, faute d'avoir été publiés, ne furent pas connus) et comme acteur (grand propriétaire foncier, il fut un " améliorateur "). Pour financer ses projets, il a toujours mené une politique financière audacieuse, en ayant recours particulièrement à la constitution de rentes.

Voyer s'était en effet mis au service de l'animal le plus noble, le cheval, et lui consacra beaucoup de temps, de réflexion, d'efforts et d'argent. Il se rendit très souvent en Angleterre où il avait de nombreuses relations, en particulier Charles-Watson Wentworth, marquis de Rockingham, propriétaire d'un célèbre haras; il y multiplia les observations sur les chevaux de course et y fit de nombreux et coûteux achats. Il souhaitait créer un " cheval de sang " français, en dépassant l'empirisme solidement établi et en s'attachant à la science zootechnique, alors portée par le mouvement agronomique. Il voulait aussi introduire en France les méthodes d'enregistrement déjà largement usitées en Angleterre qui, en donnant les généalogies ascendantes des bêtes, prouvent leurs qualités; car il ne croyait pas comme les éleveurs traditionnels au rôle des conditions géographiques et climatiques. Pour une nouvelle production répondant aux besoins, il faut de bonnes connaissances et un bon coup d'œil pour choisir les bêtes à acheter et pour repérer les bons étalons. Il n'ignorait pas que cette œuvre demanderait beaucoup de temps (il faut 5 ans pour produire un cheval, qui peut servir 10 ans), d'efforts, de persuasion et d'argent mais il était animé par le goût de l'action et du progrès; faute de moyens publics suffisants (comme en témoigne sa correspondance avec Bertin) il mit sa fortune personnelle au service de la cause qu'il défendait. Pour fournir à l'armée les différents types de chevaux dont elle avait besoin pour répondre à l'essor du Génie et de l'artillerie ainsi qu'au développement de la cavalerie légère, il proposa, en vain, une réforme du service des Haras, avec la création d'établissements régionaux spécialisés et d'un entrepôt général destiné à centraliser les achats et il démissionna en 1763.

N. de Blomac montre bien que les raisons d'une remise en question complète de la production des chevaux en France sont nombreuses. Dans la seconde moitié du siècle surtout, l'art équestre se renouvelle et naît une nouvelle culture équestre, "l'équitation "; l'évolution du vocabulaire en témoigne. Les 
auteurs, dont Bourgelat, multiplient les traités. L'armée a besoin de former les recrues au galop, allure exigeante pour la bête et l'homme, et d'apprendre aux troupes montées à galoper ensemble.

En s'appuyant sur quelques expériences déjà réalisées en France (comme à Saint-Martin-de-Vieux-Bellême), les observations faites en Angleterre où se sont développés un nouveau concept de race animale et un nouveau discours, et ses connaissances, Voyer se lance dans une œuvre ambitieuse en fondant un haras aux Ormes. Il fut servi dans cette œuvre qui commence en 1773-1774 par une très bonne équipe, avec en particulier Grandmaison inspecteur des haras pour la généralité de Tours, Rollet piqueur, et Regnier maître de postes aux Ormes et véritable intendant (sans le titre). Il achète de nombreuses bêtes en Angleterre en particulier par l'intermédiaire de Rockingham et, recherchant l'excellence, il fait constituer de précieux répertoires qui donnent pour chaque bête, nom, description précise, généalogie. Il veut mettre un nouveau cheval au service de l'équitation, de l'armée, de l'économie, mais c'est un pari risqué parce qu'il n'a aucune assurance sur ce que seront les ventes. Pour démontrer le bienfondé de son action, il contribue au développement en France des courses de chevaux, servi en cela pour l'engouement des princes du sang pour cette nouvelle distraction. On commence alors à parler de " cheval de sang " dont les qualités se transmettent par le " sang " et à accorder une grande importance au pedigree, ce qui justifie les méthodes de sélection et de " production par la reproduction ". La beauté et la bonté d'un cheval qui se manifestent dans la réussite ne relèvent pas de l'esthétique; mais beaucoup de ses acheteurs potentiels sont choqués par la maigreur des animaux proposés.

Le haras est une entreprise commerciale et Voyer ne se sent pas déshonoré d'y participer mais il réfute toute accusation de " maquignonnage "; on est d'ailleurs au temps du débat autour de la notion de liberté économique et de la Noblesse commerçante de l'abbé Coyer. Mais il souffre d'être accusé de chercher le profit à tout prix, d'autant qu'en fait il éprouve de très grands embarras financiers; il ne peut pas vendre, en particulier à l'État, ses bêtes au seul prix convenable, celui qui prendrait en compte le prix d'achat et la valeur ajoutée par l'élevage; la correspondance échangée avec Bertin le montre bien. Les propriétaires de domaines qui se sont lancés dans la même expérience (comme le comte de Rougé près de Cholet) sont dans la même situation : l'offre s'est multipliée et la demande reste très limitée. En 1781 Voyer met en vente une partie de son haras; il meurt très peu de temps après et la liquidation totale du haras suit rapidement. L'expérience se termine donc pas un échec non seulement financier mais aussi intellectuel : il n'a pas pu faire admettre ses principes zootechniques. Mais l'Empire les reprit et les mit en application.

Ce travail trouve toute sa place dans le renouveau des études sur l'élevage au XVIII ${ }^{\mathrm{e}}$ siècle et aborde un aspect mal connu. 